\title{
BRINCANDO NO LEITO: CRIANDO MÉTODOS E PERSPECTIVAS
}

Leonardo de Oliveira Barros ${ }^{1}$, Patricia Alessandra Fukura de Abreu ${ }^{2}$, Thays Mayara Alli de Andrade ${ }^{2}$, Daiane da Silva Videira ${ }^{2}$, Josiane Machado Ruiz ${ }^{2}$

${ }^{1}$ Universidade São Francisco - USF, Mestrado em Psicologia, Itatiba, SP. ${ }^{2}$ Universidade do Oeste Paulista - UNOESTE, CUrso de Psicologia, Presidente Prudente, SP. E-mail: leonardobarros lob@hotmail.com

\section{RESUMO}

A brinquedoteca hospitalar visa diminuir os aspectos negativos da internação de crianças e adolescentes, possibilitando o contato com o brincar, porém, observações in loco apontaram um grande número de crianças que não conseguem se locomover até a brinquedoteca. Esta pesquisa teve por objetivo construir um protocolo de atendimento à criança hospitalizada que necessita permanecer em repouso no leito. Participaram 56 crianças de ambos os sexos, de 0 a 17 anos, internadas na ala pediátrica de um Hospital Regional do interior do estado de São Paulo. Os dados foram coletados a partir de atividades lúdicas, autoavaliação do humor no início e final do atendimento e roteiro de registro. Constatou-se que o brincar contribuiu significativamente para melhorar o humor das crianças e adolescentes e os dados auxiliaram na elaboração de estratégias de intervenção para brinquedistas no atendimento de crianças e adolescentes acamados.

Palavras - chave: Brinquedoteca; Psicologia Hospitalar; Pediatria.

\section{PLAYING IN BED: CREATING METHODS AND PERSPECTIVES}

\section{ABSTRACT}

The hospital playroom aims to reduce the negative aspects of hospitalization of children and adolescents, allowing contact with the play, however, on-site observations indicated a large number of children who can not get around to the playroom. This research aimed to build a hospitalized child care protocol that needs to stay on bed rest. There were 56 children of both sexes, 0-17 years admitted to the pediatric ward of a regional hospital in the state of São Paulo. Data were collected from recreational activities, self-assessment of the mood at the beginning and end of care and registration script. It was found that the play has contributed significantly to improve the mood of children and adolescents and the data helped to design intervention strategies for brinquedistas in caring for children and adolescents bedridden.

Keywords: Toy; Health Psychology; Pediatrics.

\section{INTRODUÇÃO}

Quando se refere à hospitalização de crianças e adolescentes, uma série de indagações sobre os prejuízos psíquicos e a melhor conduta nesses casos são temas importantes para uma discussão ampla e profunda que tragam novas perspectivas nessa área, auxiliando na compreensão de aspectos que colaborem na recuperação do paciente. Toda hospitalização carrega um aspecto de despersonalização decorrente das regras e normas hospitalares que dificultam o enfrentamento da doença, gerando uma série de prejuízos na recuperação do internado. Os hospitais, em geral, possuem uma imagem que remete à incerteza sendo percebido como um ambiente hostil.

Nenhuma internação é fácil ou prazerosa e não é diferente para a criança ou adolescente que entra em uma pediatria. Para Viegas (2007, p. 37), o ambiente hospitalar instaura "um processo de destituição subjetiva dos pacientes, cujo efeito é paradoxal: aquilo mesmo que cura acaba também, por adoecer", ou seja, os motivos que levam a criança ou adolescentes à internação podem se agravar devido às condições que o ambiente hospitalar impõe quando estas são sentidas como ameaçadoras, frustrantes $e$ restritivas.

As crianças acabam sendo afetadas pela internação porque são afastadas da sua vida cotidiana e do seu ambiente familiar. Junto às implicações trazidas pela doença, tornam-se passivas à situação e a fragilidade vivenciada por estar longe de suas atividades cotidianas, o que pode aumentar sua angústia e seu medo, assim como, suas fantasias sobre seu estado de saúde. 
Essa ruptura com 0 cotidiano provoca sentimentos expressos no choro, na agressividade, na dependência, acarretando em ansiedade, depressão e angústia, em relação não só à sua doença, mas também à equipe que a atende, em especial, os médicos e enfermeiros, que são os profissionais responsáveis pelos procedimentos invasivos (WIEZZEL; VILLELA, 2008).

É comum reações, em que as crianças fiquem desesperadas ou submissas diante dos procedimentos a que são submetidas e da presença da equipe médica. Isso acontece porque a criança hospitalizada precisa confiar em desconhecidos dentro de uma situação também desconhecida. Os sentimentos da criança frente à internação, provenientes de seus medos e fantasias, mesclam-se aos seus sintomas, gerando certas modificações subjetivas que podem causar outros sintomas gerando mais dor e tristeza (VIEGAS, 2007).

Nesse sentido, o atendimento feito à criança hospitalizada deve acontecer em um ambiente humanizado. 0 objetivo do atendimento das equipes de saúde deve ser a promoção do bem-estar psicológico do paciente superando a visão biologista como ser que precisa apenas de reparos em seus órgãos prejudicados (PARCIANELLO; FELIM, 2008). Sabese que: "é importante que 0 atendimento hospitalar crie condições para que os indivíduos possam se expressar espontaneamente e ter contato com atividades que se contraponham à sua estrita submissão aos procedimentos técnicos" (WIEZZEL; VILLELA, 2008, p. 41).

Encontram-se, nos hospitais, crianças deprimidas, sendo de grande importância criar mecanismos que promovam um ambiente que não potencialize aspectos depressivos e que ajude a criança a enfrentar as dificuldades da hospitalização e da doença (ZANNON, 1991 apud MOTTA; ENUMO, 2004), tornando-se, também, atuante no processo de recuperação, valorizando as suas particularidades, garantindo $e$ respeitando seus direitos. $O$ adoecimento fragiliza a criança, tendo que ser submetida a dor das injeções, picadas para coleta de exames, o sono interrompido para a verificação de temperatura, entre outras situações frequentes no ambiente hospitalar que são desagradáveis, ameaçadoras e confusas para a criança. Além disso, podem ocorrer conversas entre médicos e enfermeiras próximo ao leito ondem discutem o caso clinico e planejam condutas, esquecendo-se muitas vezes que "a criança entende muita coisa e o medo aumenta" (VIEGAS, 2007, p. 49).

Tanto quanto para a criança, a hospitalização também representa uma ameaça para 0 adolescente. $O$ jovem pode reagir emocionalmente das mais diversas formas frente à internação. Em geral, expressam um sofrimento psíquico profundo, seja na apatia, seja nos momentos agressivos, na negação frente ao adoecimento ou na revolta contra a doença. A adolescência marca um momento de crise, caracterizando-se por uma fase de questionamentos e insatisfações. Uma doença pode ampliar essa atitude crítica, o que exige dos profissionais que atendem esse paciente maior conhecimento acerca dessa fase e do processo de hospitalização. O hospital também é vivenciado como um mundo estranho: "é o mundo da terminologia complexa, dos aparelhos, em que sofrem, compartilham a dor com os outros. É no hospital, também que o reconhecem e se reconhece como doente, no qual se sente preso à realidade da doença" (ALMEIDA; RODRIGUES; SIMÕES, 2005, p. 150).

Apesar de ser compreendido como grupo particular e que necessita de atendimento diferenciado, os adolescentes não encontram na rede de saúde, pública ou privada, um espaço dedicado e exclusivo a eles. Quando precisam de internação são acomodados nas pediatrias ou, em alguns casos, junto com os adultos, o que pode gerar problemas de adaptação já que esses locais não permitem uma identificação com essas faixas etárias. Almeida, Rodrigues e Simões (2007) apontam que seria adequado um espaço especifico para esse público, projetado exclusivamente para eles, com atividades lúdicas e pedagógicas que favorecessem a socialização e - lazer, bem como, capaz de propiciar os momentos de privacidade e reflexões.

Pesquisa realizada por Guzman e Cano (2000) em hospital geral, demonstrou que os adolescentes queixam-se da falta de atividades, da ociosidade vivida na internação, o que provoca irritação e apatia por passarem tanto tempo na cama, evidenciando que existe uma carência de atividades recreativas dedicadas a eles. A função dessas atividades seriam aliviar tensões físicas e mentais, possibilitando a vazão da agressividade, a auto expressão, o desenvolvimento da criatividade resultando em sentimentos de tranquilidade.

Algumas estratégias vêm sendo aplicadas nas instituições hospitalares a fim de aumentar a 
humanização nesses locais, por meio de atitudes positivas que promovam a qualidade de vida, procurando aliviar o sofrimento tanto dos pacientes como daqueles que os acompanham durante a internação. Exemplos dessas estratégias estão nas modificações que a internação infantil tem sofrido ao longo das últimas décadas, como: a mãe acompanhante que pode ficar com seu filho o tempo todo; a visita dos pais às crianças em horário livre; estímulos ao brincar; presença de voluntários que se dispõem a trabalhar de forma lúdica com as crianças e adolescentes internados e a implantação das brinquedotecas.

É importante dentro do contexto hospitalar, garantir à criança um espaço e um momento em que possa brincar, sendo esta, uma condição indispensável à sua recuperação. $O$ brincar no hospital surge como uma possibilidade de promoção do bem-estar psíquico da criança e garante seu desenvolvimento, já que possui um papel fundamental na vida infantil, tanto nos aspectos físicos como emocionais. Através do brincar, tanto a criança como o adolescente podem se expressar, amenizar conflitos e minimizar os efeitos negativos da hospitalização (WIEZZEL; VILLELA, 2008).

O brincar é uma atividade natural que faz parte da vida humana desde o início da civilização, é uma atividade social que proporciona a incorporação de valores morais e culturais, atividade imperativa tanto na vida da criança como na do adulto. É uma linguagem, uma forma de expressão que permite adaptação, interação, exploração de limites, bem como ampliação do conhecimento. Toda atividade lúdica é também composta pelo brinquedo, jogo e brincadeira, cada qual possuindo um conceito próprio que são traduzidos nos "valores, modos de vida, num dado espaço que traduz uma cultura e expressa uma linguagem própria" (UJIE, 2007, p. 2).

O brincar aparece mais evidente na vida da criança a partir de seus quatro meses de idade, até então ela esteve ocupada em explorar e conhecer o mundo a partir da sua sensorialidade. Nesse momento de seu desenvolvimento com o fortalecimento de sua capacidade motora, pode pegar os objetos à sua volta, levá-los à boca e deixá-los quando deseja, marcando o início de suas primeiras atividades lúdicas, que serão importantíssimas para o seu desenvolvimento, físico, emocional e psíquico. Brincando, as crianças aprendem e exercitam seus potenciais podendo se expressar. Tal como o adulto que se comunica verbalmente, a criança comunica-se por meio do brincar, expressam suas angústias, seus medos e anseios, nutrindo seu interior em busca de sentido para a vida (CUNHA, 2001).

Freud ensinava que uma criança brinca não somente para repetir situações satisfatórias, mas também para elaborar as que lhe foram traumáticas $e$ dolorosas [...] Ao brincar, a criança desloca para o exterior seus medos, angústias e problemas internos, dominando-os por meio da ação. Repete no brinquedo todas as situações excessivas para seu ego fraco e isto lhe permite, devido ao domínio sobre os objetos externos a seu alcance, tornar ativo aquilo que sofreu passivamente, modificar um final que the foi penoso, tolerar papéis e situações que seriam proibidas na vida real tanto interna como externamente e também repetir à vontade situações prazerosas. (ABERASTURY, 1972, p. 13-16).

Em cada etapa do desenvolvimento infantil, observa-se o aparecimento de brincadeiras diferentes que correspondem às necessidades específicas vivenciadas pela criança em determinada fase do seu desenvolvimento. Os bebês brincam com o próprio corpo e depois com os objetos. Gostam de se esconder sob lençóis, ou mesmo derrubar objetos fazendo-os "desaparecer" e "aparecer". E à medida que vão crescendo, novas brincadeiras vão se tornando interessantes ajudando-os a agir e interagir com o mundo. Essas brincadeiras que acontecem no primeiro ano de vida podem ser chamadas de jogos funcionais, que envolvem movimentos musculares repetitivos tais como rolar ou quicar uma bola, sendo facilitadoras para elaboração da ausência de sua mãe (PAPALIA, 2006).

$\mathrm{Na}$ segunda metade do primeiro ano de vida, passam a se interessar por tudo que possa ser penetrável usando os dedos para cutucar olhos, boca, orelha, nariz daqueles que estiverem perto. Por volta dos dois anos de idade, as 
brincadeiras são envolvidas pelas fantasias de união, surge o interesse por objetos esféricos, como as bolas vão aparecendo no repertório de suas brincadeiras. Entre os dois e os três anos, as brincadeiras são voltadas para as experiências de alimentação e objetos como vasilhas, pratos, vão ajudá-las a compreender as experiências de perda e recuperação. Nessa fase, inicia o controle esfincteriano e, por isso, o corpo passa a ter um interesse especial, o desenho aparece como forma para expressar suas preocupações podendo representar de maneira simbólica objetos animados e inanimados. Conforme avança o desenvolvimento, as crianças tendem a se tornarem mais interativas e cooperativas. Inicialmente, brincavam sozinhas e depois ao lado de outras crianças para então realizarem as brincadeiras em conjunto (PAPALIA, 2006).

Por volta dos cinco anos, as brincadeiras de meninos e meninas começam a se diferenciar. Os meninos, em geral, apreciam as brincadeiras de ação, enquanto as meninas preferem brincadeiras mais tranquilas. Nessa etapa que se dá a inserção das crianças na vida escolar e as brincadeiras passam a envolver letras, números e jogos, auxiliando-as a compreender a vida social por meio dos jogos que ensejam o sucesso ou o fracasso a partir do desenvolvimento de habilidades e o conhecimento das regras. Com a entrada na latência, por volta dos sete ou oito anos, as brincadeiras novamente voltam-se ao uso do próprio corpo, evidenciando as brincadeiras de luta, corrida e futebol. Os brinquedos são deixados de lado, sendo substituídos pelas experiências amorosas, pois é nessa fase que meninos e meninas passam a "conhecer e aprender as funções de cada sexo" (ABERASTURY, 1972, p. 84). Com a adolescência, os brinquedos são abandonados, assim como o corpo de criança.

A partir do aprofundamento da função do brincar no desenvolvimento infantil, pode-se afirmar que o brincar é saúde, contribuindo para a recuperação durante a internação. De acordo com Lindquist (1993), a criança requer cuidados individuais mais ainda que o adulto, porque nem sempre vai dizer o que sente ou incomoda quando está internada. Segundo Mitre e Romeu (2004, p. 153) "o brincar pode ser percebido pelos profissionais de saúde como um instrumento de facilitação no processo de trabalho para se lidar com o sofrimento". Nesse sentido, a criança que brinca aparenta não estar tão doente ainda que num breve espaço de tempo. O lúdico surge como possibilidade de se construir algo de positivo ou bom num momento de perdas.

O ato de sair da cama para brincar já é terapêutico ao dar a criança condições para agir e reagir frente a situações adversas e estressantes da hospitalização. No caso de crianças que não podem ir até a brinquedoteca, por motivos diversos que vão desde a criança se encontrar na fase terminal, ter se submetido a procedimento cirúrgico recentemente, ou seu corpo estar incapacitado de sair do leito, esta deve receber a visita dos brinquedistas no leito devendo ser levado até ela uma grande seleção de brinquedos (LINDQUIST, 1993). Porém, nem sempre todo tipo de brinquedo é apto, muitas vezes demanda adaptações nas brincadeiras e jogos e também improvisos: a escada vira banco para o brinquedista, a cômoda que está presente no quarto e tem rodas, vira mesa para jogos, as crianças que podem locomover-se com liberdade muitas vezes querem brincar com aquelas que não podem deixar a cama, o que também exige do brinquedista criatividade para manejar tal situação.

Por isso, é interessante procurar por métodos que possam contribuir para a diminuição do sofrimento das crianças internadas, principalmente daquelas que se encontram acamadas. Esses métodos devem ter por função encontrar perspectivas de ampliar a brinquedoteca para toda a pediatria, sendo essa ala do hospital um lugar agradável, que promova saúde, levando alegria e diversão para todos, principalmente para aqueles que se encontram "impossibilitados" de locomover-se ou com baixa energia para atividades lúdicas.

Pesquisas como a de Parcianello e Felin (2008) têm demonstrado a necessidade de um local específico e estruturado que ofereça as atividades lúdicas, porém, é importante destacar o que aponta Chiattone (2003) ao sugerir que o psicólogo deve levar até a criança que está no leito, em repouso, diversas atividades lúdicas. O repertório do brincar no leito exige certa sistematização, no sentido de que a atividade precisa ser adequada a real possibilidade e limitações da criança para que ela possa brincar durante a internação, visando minimizar os seus aspectos negativos e ampliando as condições de melhora desses pacientes. Os profissionais devem estar preparados e equipados para realizar atividades lúdicas dentro da brinquedoteca com as crianças que até lá podem 
ir e, principalmente, no leito onde a demanda pelo brincar é evidentemente grande e necessária.

Historicamente, a brinquedoteca foi criada no início apenas para o empréstimo de brinquedos e, com o tempo, evoluiu de acordo com as necessidades de cada país, trazendo assim uma diversidade de serviços. Seu objetivo é proporcionar o desenvolvimento das atividades lúdicas e a valorização do brincar, independente do tipo e local que elas se encontram. No Brasil, no ano de 1985, foi criada a Associação Brasileira de Brinquedotecas (ABB) que, conforme Ramalho e Silva (2003, p. 27-28), conceituam brinquedotecas como "espaços mágicos destinados ao brincar das crianças e alerta para o fato de que não podem ser confundidas com um conjunto de brinquedos ou depósito de crianças". Dentre as diversas modalidades de brinquedotecas, encontra-se a hospitalar, localizada geralmente no setor da pediatria do hospital, no qual as crianças hospitalizadas podem ir brincar. Os brinquedos ficam expostos podendo ser levados ou não para os leitos, dependendo das condições clínicas do paciente. Um dos objetivos da brinquedoteca dentro do hospital é auxiliar na recuperação e amenizar o trauma psicológico da hospitalização através de atividades lúdicas.

As brinquedotecas hospitalares se tornaram obrigatórias, amparadas pela lei no 11.104 de 21 de Março de 2005 (BRASIL, 2005), no qual dispõe sobre a obrigatoriedade de instalação de brinquedotecas nas unidades de saúde que oferecem atendimento pediátrico em regime de internação. Considera-se brinquedoteca, para os efeitos desta lei, um espaço provido de brinquedos e jogos educativos, destinado a estimular as crianças e seus acompanhantes a brincar. Mitre e Romeu (2004, p.151) dizem que: "sendo o brincar uma linguagem universal e que remete ao prazer e à alegria, ele acaba se estendendo para os familiares, para os próprios profissionais que estão ali diariamente em contato com as crianças". Desse modo, as brinquedotecas hospitalares são um espaço de humanização, promovendo o divertimento da criança, dos adultos, assim como, dos profissionais de saúde.

Compreendendo a necessidade de contemplar as crianças impossibilitadas de saírem do leito e irem para a brinquedoteca hospitalar, torna-se importante refletir sobre a forma de propiciar o contato com o lúdico nessas condições. Assim, esta pesquisa teve como objetivo construir um protocolo de atendimento do brinquedista à criança hospitalizada que necessita permanecer em repouso no leito, assim como, coletar dados através de um roteiro para identificar as brincadeiras que mais estimulam as crianças e possam favorecer a melhora física e psicológica; propor brincadeiras adequadas de acordo com a idade, condição de saúde e a situação do leito e, por fim, subsidiar o trabalho de binquedistas hospitalares na formatação de suas estratégias de intervenção.

\section{MÉTODO}

Este trabalho teve caráter qualitativo descritivo cujo modelo de pesquisa é definido por Neves $(1996$, p. 1) como "direcionada ao longo de seu desenvolvimento, além disso, não busca enumerar ou medir eventos e, geralmente, não emprega instrumental estatístico para análise de dados". Faz parte doo método qualitativo a obtenção de dados descritivos mediante contato direto e interativo do pesquisador com a situação/objeto de estudo.

\section{Participantes}

Participaram do estudo 56 crianças que totalizaram 60 atendimentos entre os meses de agosto a dezembro de 2013. Os participantes tinham idades de 0 a 17 anos e 11 meses, sendo 12 do sexo feminino e 44 do sexo masculino, internados no setor de pediatria de um Hospital Regional do interior do Estado de São Paulo.

\section{Instrumentos}

Quadro do humor: desenvolvido pelos integrantes da pesquisa, o quadro é confeccionado com espuma vinílica acetinada (EVA) e contém três opções de humores: alegre, indiferente e triste. Os humores estavam retratados em três expressões faciais que representavam cada um dos humores respectivamente.

Recursos lúdicos: utilizou-se brinquedos, jogos, materiais gráficos que estavam a disposição na brinquedoteca hospitalar.

Protocolo de atendimento: folha de registro onde consta nome do brinquedista, data, horário de início e término da sessão, nome da criança, motivo da internação, acompanhante, avaliação do sentimento da criança no início e no final do atendimento, tipo de atividade realizada, observações e conclusões. 
Quadro 1. Modelo de protocolo de atendimento

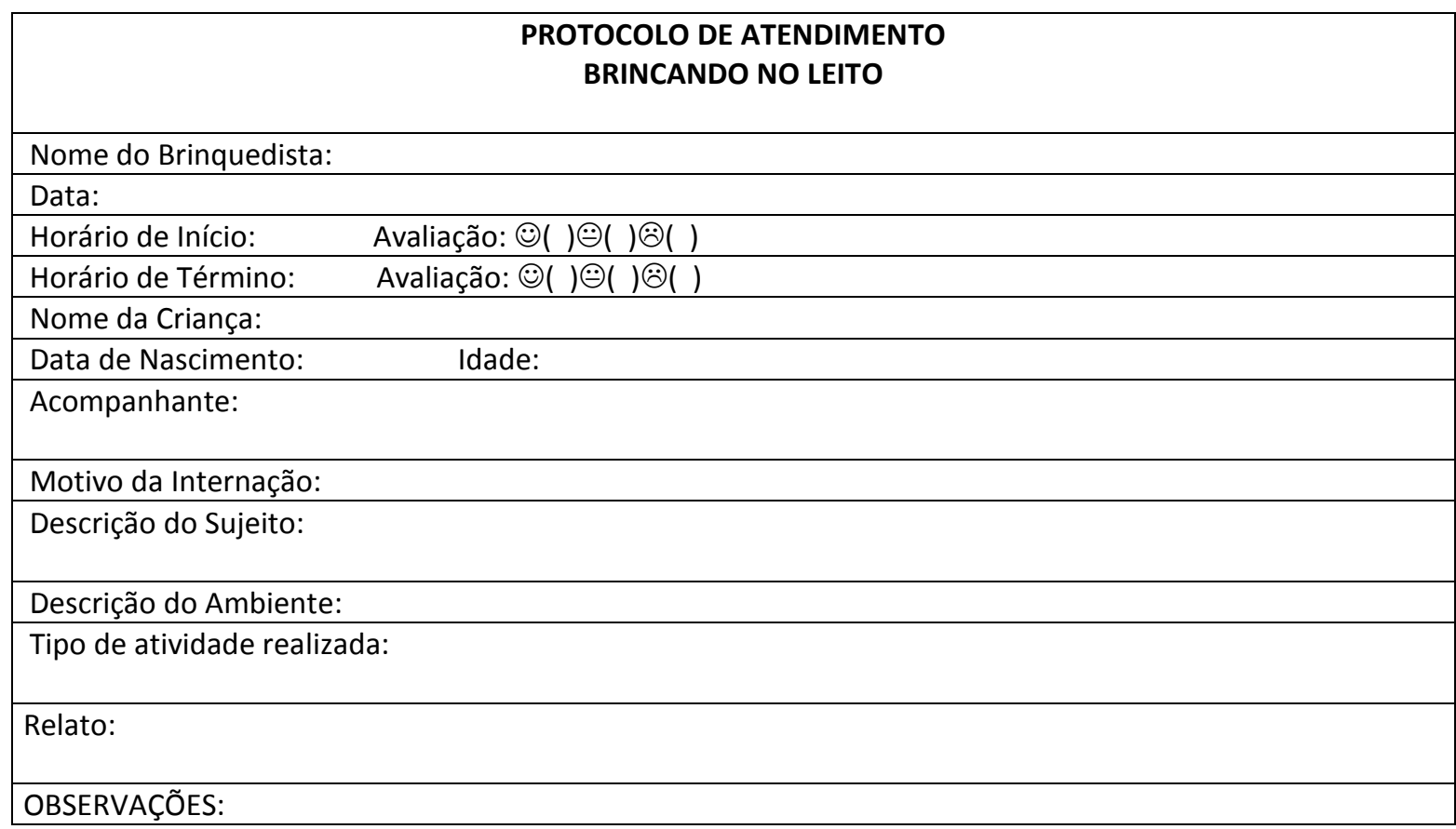

Fonte: Autores da pesquisa

\section{Procedimentos}

Após consentimento do local onde a pesquisa foi realizada, o projeto de pesquisa foi aprovado pelo Comitê de Ética em Pesquisa da Universidade do Oeste Paulista (protocolo CCPq 1646). Por se tratar de crianças e adolescentes, os responsáveis pelos participantes também assinaram o Termo de Consentimento Livre e Esclarecido e, assim como os participantes, receberam orientações acerca dos objetivos do estudo. No início do atendimento, a criança/adolescente foi estimulada a identificar o sentimento que vivenciava, através do Quadro do Humor. Após esse contato inicial, o brinquedista realizou brincadeiras com a criança no leito no período de 40 minutos aproximadamente. Decorrido o atendimento, estimulou-se a criança a novamente identificar o seu sentimento, apresentando-Ihe novamente o Quadro de Humor. Posteriormente, o brinquedista preencheu o protocolo de atendimento.

\section{Análise dos dados}

Os dados coletados deram subsídios para uma análise qualitativa das atividades realizadas, verificando qual tipo de brincadeira trouxe a criança maiores sentimentos de alegria, descontração, tédio ou cansaço, qual o tempo suficiente para a realização da atividade com a criança e quais situações demandava recursos de apoio para a execução da brincadeira. A partir dessas categorizações, foi possível apontar modos de atuação do brinquedista no atendimento de crianças e adolescentes acamados, de acordo com a condição de saúde, idade e situação de internação.

\section{RESULTADOS E DISCUSSÕES}

A partir dos dados coletados, torna-se possível refletir acerca do perfil das crianças atendidas e propor métodos e novas perspectivas para a atuação de brinquedistas em relação ao atendimento de crianças acamadas. Inicialmente, serão apresentados os dados descritivos sobre a população atendida e, posteriormente, uma análise qualitativa dos casos.

Em relação à idade e sexo das crianças atendidas. Verifica-se que os atendimentos foram, em sua maioria, realizados com meninos, sendo que estes estiveram presentes na faixa de zero a 17 anos, ao contrário das meninas, minoria atendida, e sem representantes na faixa etária de 16 a 18 anos. Assim, a amostra foi composta por nove meninos e quatro meninas na faixa dos zero aos cinco anos, 13 meninos e cinco meninas na faixa dos seis aos 10 anos, 19 meninos e 3 meninas entre 11 e 15 anos e apenas três meninos na faixa de 16 a 17 anos e 11 meses.

A justificativa para essa diferença pode ser encontrada nos motivos de internação dos 
participantes. Tendo em vista que os atendimentos foram realizados com crianças impedidas de saírem do leito seja por determinantes de doenças ou por baixa energia, verificou-se que as fraturas foram as maiores causas de impedimento de locomoção na internação infantil onde a pesquisa foi realizada, totalizando 19 crianças atendidas. Desse ponto de vista, pode-se traçar uma correlação entre sexo e motivo da internação. Meninos optam por atividades mais concretas e realísticas, nas quais há a presença da força física e da alta atividade motora, ao contrário das meninas que optam mais por atividades no plano do simbólico nos quais o faz-de-conta é mais presente, sem grandes combates com seus pares ou intensas atividades motoras no seu brincar (WANDERLIND et al., 2006). Dos meninos hospitalizados por fraturas, apenas três são decorrentes de acidentes automobilísticos, todos os outros sofreram as lesões em suas atividades diárias, entre elas, o brincar.

Cirurgias de apendicite aparecem em segundo lugar no índice de frequência, totalizando 11 atendimentos. Os demais fatores de internação aparecem com apenas um ou dois representantes, sendo composto por doenças respiratórias, infecções, diabetes, doenças renais, convulsões, febre, vômito, dores corporais e doenças infecto contagiosas como a tuberculose.

Compreender os motivos da internação é fundamental para o momento em que se propõe uma atividade para a criança acamada, devendose levar em consideração as limitações e possibilidades efetivas do brincar em sua situação de hospitalização. Nesse sentido, a Tabela 1 apresenta as atividades realizadas de acordo com categorias de idades.

Tabela 1. Atividades realizadas de acordo com a faixa etária

\begin{tabular}{|l|l|l|l|}
\hline $\mathbf{0 - 5}$ anos & $\mathbf{6 - 1 0}$ anos & $\mathbf{1 1 - 1 4}$ anos & $\mathbf{1 5 - 1 8}$ anos \\
\hline Desenho/Pintura & Desenho & Desenho & Desenho \\
Jogo da memória & Jogo da memória & Jogo da memória & Jogo da memória \\
Quebra-cabeça & Quebra-cabeça & Dominó & Dominó \\
Damas & Dobradura & Damas & Damas \\
Rasgar papel & Uno & Uno & Xadrez \\
Animais & Stop & Stop & \\
Bola, blocos, Lego & Lego & Dobradura & \\
Jogo da velha & Banco Imobiliário & Jogo da velha & \\
Bonecas e bonecos & & Banco Imobiliário & \\
Casa de Boneca & & Gibi e livros & \\
Carrinhos/ barcos & & & \\
Trenzinho & & & \\
\hline
\end{tabular}

Fonte: Autores

Com as crianças de 0 a 5 anos predominam atividades que estimulem a motricidade fina, por meio de estimulações sensoriais e manuseio de brinquedos de formas variadas. Conforme o nível de desenvolvimento da criança, foram propostos jogos de raciocínio de baixa complexidade. Com os participantes de 6 a 10 anos, houve uma preferência maior por atividades em que o brincar não fosse tão individualizado, havendo uma interação direta com o brinquedista e, possibilitando o desenvolvimento de atividades grupais. Assim, aparecem os jogos estruturados que demandam parceiros para sua execução.

Dos 11 aos 15 anos, as preferências sofrem algumas alterações com a entrada de jogos mais complexos e a leitura. As atividades possibilitaram o desenvolvimento de atendimentos individuais e grupais, sendo que, somente nos casos em que foram solicitados livros o brinquedista foi dispensado pela criança. Desses casos, apenas um optou diretamente pela leitura e outro solicitou livros ao final do atendimento. Por fim, os adolescentes de 15 a 17 anos optaram por atividades em que o brincar fosse apenas mediador para que pudessem conversar com os brinquedistas. Com essa faixa etária, verificou-se a necessidade de um espaço onde pudessem falar sobre suas vivências anteriores e próprias da internação, assim como, das expectativas pós-hospitalização. Merece destaque que o brinquedista com formação em Psicologia, deve estar atento para manter-se em um papel de brinquedista com o objetivo de levar o brincar até essas crianças, sem deixar que os atendimentos tomem caráter psicoterapêutico. 
No espaço hospitalar, ao propor uma atividade lúdica para a criança, espera-se que esta contribua para o rompimento de sentimentos negativos próprios da internação. A fim de verificar o efeito do brincar para as crianças acamadas, realizou-se uma investigação de humor antes e após o período de atendimento, sendo os resultados apresentados na Figura 1.

Inicialmente, 15 crianças avaliaram o seu humor como indiferente, ou nas palavras de algumas delas, entediado. Ao final do atendimento, apenas cinco crianças continuaram nessa categoria. Em relação ao sentimento de tristeza, 14 crianças se identificaram como tristes no início do atendimento e ao final, apenas duas permaneceram com essa avaliação. Estas justificaram que desejavam ir embora do hospital, atribuindo a esse motivo a escolha de um humor triste ao final do atendimento.

O efeito do brincar foi positivo para a maioria das crianças, uma vez que, inicialmente 32 se autoavaliaram como felizes no início do atendimento e ao final o número chegou a 53 crianças. Esse dado corrobora com a literatura que aponta o efeito benéfico do brincar para as crianças, possibilitando o enfrentamento de situações conflituosas, a diminuição de ansiedades, sendo também um espaço e meio adequado para que consigam expor o que estão sentindo, minimizando os aspectos negativos da hospitalização.

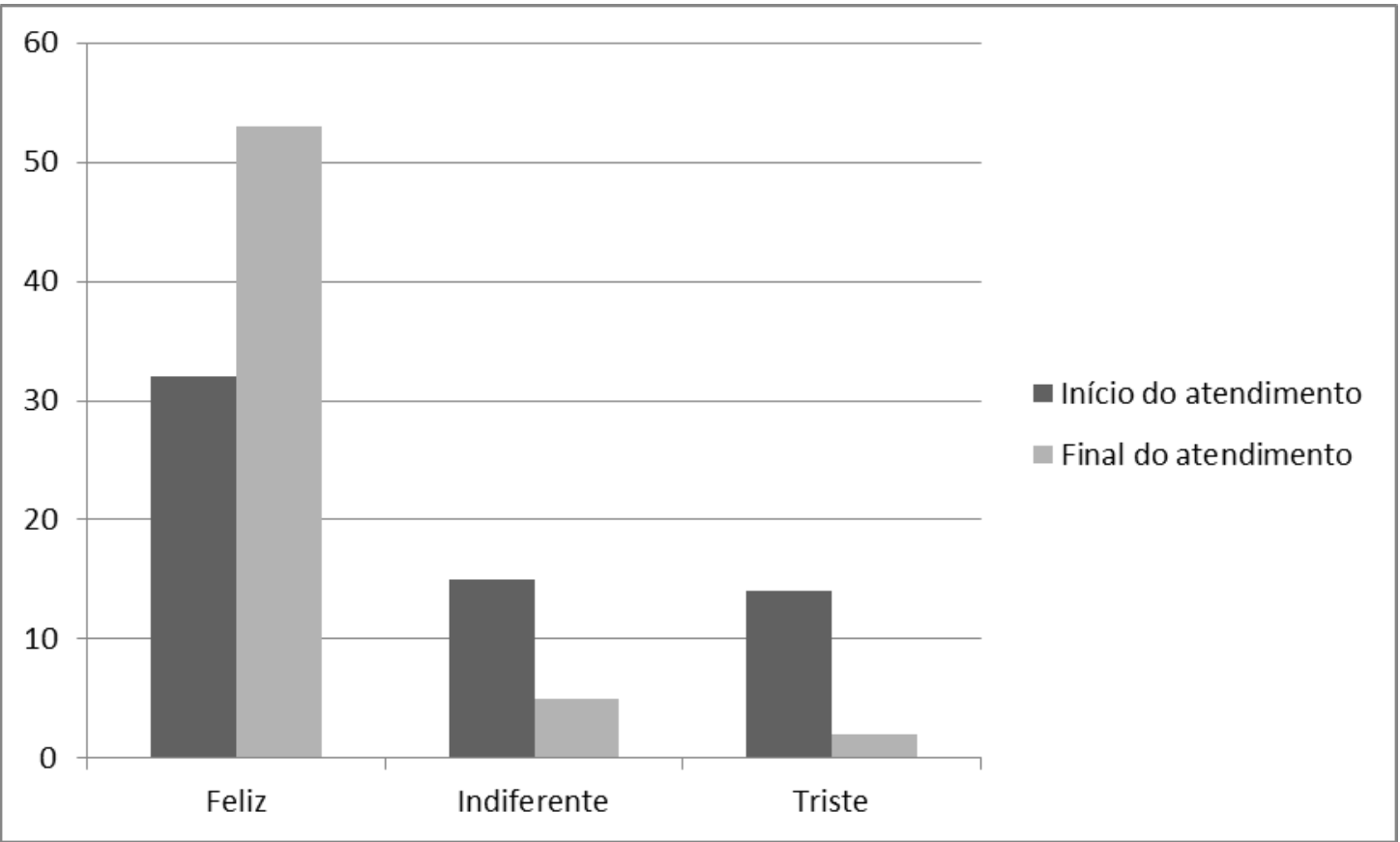

Figura 1. Avaliação do humor no início e final dos atendimentos (Fonte: Dados trabalhados pelos pesquisadores)

Muitas outras considerações podem ser realizadas, sendo que, neste momento, é preciso realizar uma análise qualitativa dos dados coletados nos atendimentos. Para facilitar a compreensão e a sistematização, optou-se por dividir os atendimentos em faixas etárias.

\section{$O$ atendimento de crianças de 0 a 5 anos}

As crianças pequenas, em geral, recebiam bem os brinquedistas quando estes se apresentavam trazendo estímulos para o brincar, como bonecos nos bolsos do jaleco, blocos, carrinhos, ou papeis e lápis nas mãos. Os brinquedos preferidos eram aqueles mais coloridos, barulhentos e que podiam ser colocados em movimento, corroborando com os pressupostos de Papalia (2006) acerca do brincar nessa faixa etária. As crianças ao se depararem com uma variedade de brinquedos, sentiam-se empolgadas e ansiosas por brincar, algumas vezes esquecendo-se de suas limitações, como a tala no braço.

No princípio desse trabalho, os médicos e equipe de enfermagem ignoraram a presença dos brinquedistas nos leitos. Conforme o trabalho foi ganhando visibilidade e também consistência, essa atitude da equipe foi mudando na ala pediátrica. Os brinquedistas passaram a ser, 
inclusive, solicitados para esse tipo de atendimento, visto o reflexo que o mesmo provocava nas crianças. $O$ próprio atendimento da equipe era facilitado, uma vez que a criança hospitalizada nessa faixa etária ficava mais tranquila após a intervenção realizada. Cabe ressaltar que a atuação dos brinquedistas estava sempre a serviço da criança ou adolescente atendido e que o atendimento não se configurou como estratégia de distração para procedimentos invasivos. A solicitação dos atendimentos por parte da equipe médica para esta faixa etária foi entendida como aspecto positivo, evidenciando que houve uma conscientização acerca da importância do brincar nesse espaço.

\section{$O$ atendimento de crianças de 6 a 10 anos}

As crianças entre seis e dez anos, em geral, mantinham-se tímidas no momento da abordagem, não demonstrando iniciativa para a escolha da atividade, sendo inevitável que os brinquedistas oferecessem uma ampla variedade de opções de atividades lúdicas. Os jogos estruturados foram os preferidos nessa faixa etária, seguidos pelo desenho livre.

Essas características confirmam os pressupostos de Aberastury (1972) em que, nessa faixa etária, equivalente à latência, verifica-se que a criança vive um momento intermediário entre a infância e a adolescência passando a se interessar por atividades como jogos, brincadeiras e apresentando atitudes como vergonha e moralidade. Neste estágio do desenvolvimento emocional, meninos e meninas procuram ficar em grupos isolados de acordo com o sexo e utilizam sua energia psíquica para conhecer e aprender sobre regras de convívio social, cultura e todo aprendizado concentrado no campo escolar.

Nessa idade, o manejo da abordagem inicial demandou maiores habilidades do brinquedista, como a criatividade, a forma de se relacionar, dialogar e disposição para entusiasmar a criança. Também foram encontradas crianças com necessidades especiais, internadas na ala pediátrica e, nesses casos, mais uma vez, observou-se a necessidade de muita criatividade por parte dos brinquedistas no atendimento, principalmente para uma comunicação clara com os participantes.

$O$ atendimento de crianças de 11 a 14 anos

Os atendimentos nessa faixa etária corresponderam, em sua maioria, por meninos que haviam sofrido de acidentes automobilísticos resultando em fraturas ósseas. Esses eram os casos que especialmente demandavam o trabalho dos brinquedistas nos leitos, porque esses jovens estavam com ataduras, gessos, pinos, braços ou pernas suspensos, e por isso locomover-se era algo quase impossível.

Nessa faixa etária, jogos como Uno, memória, banco imobiliário, eram os mais solicitados. Evidenciou-se que a atividade lúdica era apenas um mediador para que pudessem conversar e que a abordagem deveria ser de forma a não se sentirem infantilizados, sendo preferível convidá-los a jogar ao invés de brincar. Em função do motivo de internação, foi necessário modificar o leito para que se atingissem as condições necessárias para jogar. Assim, providenciaram-se suportes para colocarem as cartas ou peças, bem como, posicionar os jogos próximos ao braço do adolescente que tinha seus movimentos limitados e, em algumas situações, o brinquedista jogava para o jovem a partir de seu comando.

Uma situação constante na ala pediátrica é a presença de aparelhos tecnológicos trazidos pelos acompanhantes para que a criança se distraia durante a internação. Desse modo, foi preciso mostrar para as crianças o quão prazeroso pode ser realizar uma atividade lúdica por meio do brinquedo ou jogos. É importante possibilitar que os aparelhos tecnológicos sejam utilizados de forma saudável no ambiente hospitalar, não prejudicando as interações sociais ou o desenvolvimento infantil.

\section{$O$ atendimento em grupos}

Os atendimentos realizados em grupos aconteceram de forma espontânea, uma vez que, inicialmente, não havia pretensão de atendimento coletivo. Abordava-se uma criança e isso despertava o interesse dos demais presentes no quarto que demonstravam vontade em participar da atividade, com isso os brinquedistas reuniam estas crianças convidando-as a jogos nos quais todos pudessem participar. Os grupos foram compostos sempre com a presença de um adolescente e as atividades realizadas constituíram-se em jogos estruturados como uno, jogo da memória e dominó. Por meio dos grupos, novas relações foram se formando entre as crianças e adolescentes, mediado também pelos jogos.

Esse movimento que estas crianças fizeram ao se reunirem causa a impressão de 
uma transformação geral dentro do quarto. A perspectiva de cada um deitado em sua cama é quebrada e uma nova configuração surge bem mais próxima da vida deles e de seu estágio de desenvolvimento. Como se sabe, o grupo passa a ter uma importância especial na adolescência (ABERASTURY, 1972). Verificou-se que permanecer no leito é bastante monótono para a criança e o adolescente, que se surpreende com a possibilidade de fazer algo prazeroso durante a hospitalização como reunir-se para jogar.

Essa aproximação e interação entre as crianças abriram diálogos sobre diversos assuntos de interesses comuns, que permitiram diminuir a preocupação provocada pela situação de internação. Em alguns casos, os acompanhantes se envolveram com a brincadeira, participando dela diretamente ou apenas observando, sendo evidenciado o desligamento momentâneo da tensão causada pela internação.

Em geral, os acompanhantes estão preocupados com o bem-estar da criança e/ou adolescente, alguns até superprotegendo-os. Os brinquedistas precisam também mediar o jogo, possibilitando a autonomia da criança frente a suas limitações e esclarecendo, sempre de maneira amena, que a criança pode à sua maneira realizar suas atividades e que os adultos devem respeitar os limites da criança, não interferindo ou impedindo que eles realizem suas jogadas. Assim, a participação dos acompanhantes nos grupos possibilitou a estes um ganho na relação com o internado, diminuindo seu sentimento de culpa e superproteção.

Em algumas situações, os acompanhantes auxiliam na organização do quarto de modo a possibilitar a execução da brincadeira. O maior ganho nos atendimentos grupais foi a socialização dos participantes que dividiam o mesmo quarto, mas não se conheciam ou até mesmo não haviam interagido ainda. Quando reunidos para jogar, acabaram encontrando afinidades, histórias comuns e se ajudando mutuamente. A atividade lúdica abre diálogos e possibilita a criação de laços, tão importantes à melhora do internado e à relação daqueles que convivem no quarto.

\section{CONSIDERAÇÕES FINAIS}

Esse trabalho tornou-se importante pela possibilidade de sistematizar os atendimentos às crianças hospitalizadas que estão impossibilitadas de sair do quarto para dirigir-se à brinquedoteca pediátrica. Através do registro do protocolo, foi possível identificar as brincadeiras que mais aconteciam e em que faixa etária elas eram mais comuns, respeitando as limitações das crianças. Esse levantamento possibilitou uma melhor adequação quanto ao tipo de brinquedo a oferecer, como abordar e realizar a brincadeira no leito.

As crianças pequenas precisavam de brinquedos mais coloridos, com sons, que chamassem a atenção de alguma maneira; as crianças com mais de seis anos optavam por brincadeiras estruturadas nas quais começava a aparecer o interesse por jogos e os adolescentes utilizavam-se dos jogos como mediador para diálogos, demonstrando a necessidade de conversar.

A abordagem foi um fator que reuniu a atenção dos brinquedistas, pois é sabido que as crianças hospitalizadas costumam se assustar com a presença de pessoas vestindo jaleco branco, logo imaginam que passarão por algum procedimento médico. Além disso, foi possível perceber que a aproximação dos brinquedistas dos bebês, das crianças e dos adolescentes apresentavam diferenças. Com os bebês era preciso uma aproximação tranquila e uma apresentação de estímulos variados; com crianças pequenas convida-se para brincar, oferecendo uma ampla opção de brincadeiras e com os adolescentes era preciso uma linguagem e postura diferente denominando a atividade como jogo para que não se sentissem infantilizados e aceitassem participar do atendimento.

Esses atendimentos favoreceram significativamente a melhora do humor dessas crianças, amenizando seu sofrimento diante da internação, demonstrando a importância desse tipo de trabalho, que não era realizado anteriormente na ala pediátrica do referido hospital. A partir do momento que existiu o interesse dos brinquedistas pelas crianças acamadas, uma modificação aconteceu naquele espaço. Essas crianças necessitam de uma atenção tanto quanto ou até maior do que as crianças que podem locomover-se dentro daquele espaço.

Sobre o tempo de atendimento, constatou-se que para a modalidade individual um tempo médio de 40 minutos é suficiente para a realização de atividades e permite também abordar outras crianças da ala pediátrica. Quando o atendimento é na modalidade grupal, sugere-se 
um tempo de uma hora e trinta minutos em média, em função das atividades demorarem mais tempo por se tratarem de jogos estruturados e até mesmo pela realocação dos participantes no espaço físico. O intervalo de tempo que acontece o atendimento não é fixo, mas observou-se que faz um ciclo que compreende a abordagem, a própria brincadeira/ jogo e sua finalização.

Em relação ao número de brinquedistas por atendimento notou-se que quando apenas uma criança e/ou adolescente está sendo atendido, dois brinquedistas são um número suficiente, permitindo maior estimulação e desenvolvimento da criatividade, assim como uma situação agradável e não assustadora para a criança. Em atendimentos grupais, é possível aumentar o número de brinquedistas, de modo a permitir que todas as crianças recebam atenção e que as dificuldades de organização da atividade sejam sanadas facilmente.

Aponta-se a necessidade de novos estudos que visem desenvolver estratégias de intervenções em todos os espaços das alas pediátricas. Espera-se que os leitos das pediatrias sejam preenchidos com brincadeiras e não sejam esquecidos pelos brinquedistas. Toda criança precisa brincar, independente das limitações que estejam vivenciando e é importante que exista um mediador que abra a possibilidade de brincar no leito.

\section{REFERÊNCIAS}

ABERASTURY, A. A criança e seus jogos. Rio de Janeiro: Vozes, 1972.

ALMEIDA, I. S.; RODRIGUES, B. M. R. D.; SIMOES, S. M. F. Desvelando o cotidiano do adolescente hospitalizado. Revista Brasileira de Enfermagem, v.58, n.2, p.147-151, 2005. http://dx.doi.org/10.1590/S0034-

71672005000200003

$$
\text { . Hospitalização }
$$

do

adolescente. Revista Brasileira de Enfermagem, v.7, n.1, p.33-39, 2007.

BRASIL. Lei no 11.104, de 21 de março de 2005. Dispõe sobre a obrigatoriedade de instalação de brinquedotecas nas unidades de saúde que ofereçam atendimento pediátrico em regime de internação. Brasília: Casa Civil, 2005.
CHIATTONE, H. B. C. A criança e a hospitalização. In: ANGERAMI-CAMON, V. A. (org.); CHIATTONE, H. B. C.; MELETI, M. R. A psicologia no hospital. 2. ed. São Paulo: Pioneira Thomson Learning, 2003. p. 23-100.

CUNHA, N. H. S. Brinquedoteca: um mergulho no brincar. 3. Ed. São Paulo: Vetor, 2001.

GUZMAN, C. R; CANO, M. A. T. O adolescente e a Hospitalização. Revista Eletrônica de Enfermagem, v.2, n.2, 2000. Disponível em: <www.fen.ufg.br/revista/revista2_2/v2n2.htm>. Acesso em: 20 ago. 2013.

LINDQUIST, I. A criança no hospital: terapia pelo brinquedo. São Paulo: Página Aberta, 1993.

MITRE, R. M. A; ROMEU, G. A promoção do brincar no contexto da hospitalização infantil como ação de saúde. Ciênc. Saúde Coletiva, Rio de Janeiro, v.9, n. 1, 2004.

MOTTA, A. B; ENUMO, S. R. F. Brincar no hospital: Estratégia de enfrentamento da hospitalização infantil. Psicologia em Estudo, Maringá, v.9, n.1, p.19-28, 2004. http://dx.doi.org/10.1590/S141373722004000100004

NEVES, J. L. Pesquisa qualitativa - características, uso e possibilidades. Cadernos de Pesquisa em Administração, v.1, n.3, 2ㅇsem. 1996.

PAPALIA, D. E. (cols). Desenvolvimento humano. 8. ed. Porto Alegre: Artmed, 2006.

PARCIANELLO, A. T.; FELIN, R. B. E agora doutor, onde vou brincar? Considerações sobre a hospitalização infantil. Barbarói, n.28, p.147-166, 2008.

RAMALHO, M. R. B; SILVA, C. C. M. A brinquedoteca. Revista ACB: Biblioteconomia em Santa Catarina, v.8, n.1, p.26-34, 2003.

VIEGAS, D. (Org.). Brinquedoteca hospitalar: isto é humanização. Rio de Janeiro: Wak, 2007.

UJIIE, N. T. Ação lúdica na educação infantil. Colloquium Humanarum, v.4, n.1, p. 01-07, jun. 2007.

WIEZZEL, A. C. S; VILLELA, F. C. B. A brinquedoteca e o brincar no hospital: dialogo 
entre o lúdico e o terapêutico. Nucleus, v.5, n.2, out. 2008.

http://dx.doi.org/10.3738/1982.2278.129

WANDERLIND, F. et al. Diferenças de gênero no brincar de crianças pré-escolares e escolares na brinquedoteca. Paidéia, v.16, n.34, p.263-273, $2006 . \quad \quad h t t p: / / d x . d o i . o r g / 10.1590 /$ S0103$863 \times 2006000200014$

Recebido para publicação em 31/08/2015

Revisado em 07/03/2016

Aceito em 07/06/2016 